\title{
HIV and Swine Flu: A Short Summary
}

\author{
Viroj Wiwanitkit* \\ Surin Rajabhat University, Surin, Thailand
}

Received: March 26, 2015; Accepted: June 16, 2015; Published: June 25, 2015

*Corresponding author: Viroj Wiwanitkit, Wiwanitkit House, Bangkhae, Bangkok, Thailand, Pin-10160; Email: wviroj@yahoo.com

\begin{abstract}
Emerging swine flu (H1N1) influenza has become the public health concern since its first appearance in 2009. The clinical issue of swine flu in immunocompromised host is very interesting. In this brief article, the author summarizes on the clinical feature of swine flu in HIV infection cases.
\end{abstract}

Keywords: HIV, Swine, Flu

\section{Introduction}

Emerging influenza is the global issue. The infection is a respiratory tract disease with additional atypical systemic presentation $[1,2]$. Due to the possible worldwide pandemic, the topic becomes hot issue at present. Emerging swine flu (H1N1) influenza has becomes the public health concern since its first appearance in 2009. This new emerging infection affects several countries around the world and it is still the present public health problem $[1,2]$. During a pandemic, there are many thousand infected cases around the world. Some infected cases have underlying medical disorders and this is the issue for further study in infectious medicine.

The clinical issue of swine flu in immunocompromised host is very interesting. In fact, the immunity of the patients can play important role in response to any infection including to swine flu. The patient with poor immune status usually has problem in response to infection and the more severe clinical sign and symptom is usually observed. In this brief article, a clinical feature of swine flu infection in HIV infected cases is mainly focused. In fact, up to $2.22 \%$ of the patients with swine flu have HIV infection as underlying medical disorder [3]. It is no doubt that the HIV in swine flu is an important issue. However, there are few reports on this specific topic and there is no summary with appraisal on the topic. Here, the authors summarize the clinical data presently available in case of concurrent swine flu infection and HIV. The standard literature searching by publicly available databases, PubMed, was done. The search terms include "HIV" and "swine flu". Conclusions are based on the derived information from the literature available. In Addition, the author also analyzes and discusses on how the information can be further used in the field.

\section{Swine Flu in HIV Infected Case}

As a disease with worldwide spreading, it is no doubt that swine flu affects many patients with underlying medical disorders. The HIV infection becomes an interesting medical disorder that the swine flu infection should be carefully studied. For sure, there are many reports on HIV infected patients with swine flu. To manage the specific case, CDC mention for the importance of early diagnosis and prompt treatment for the HIV infected patients $[4,5]$. Due to the impaired lymphocyte function, it is expected that the superimposed viral infection can be serious and the use of antiviral drug is indicated for early management $[2,4]$. Koegelenberg et al. Reported that HIV infection is an underlying medical condition that leads to the requirement of intensive respiratory support and mortality in patients with swine flu [6]. Kulkarni et al. Also reported a similar observation [7]. Nevertheless, the early use of antiviral drug seems to be effective in the HIV infected cases [8]. Peters et al. Concluded that "clinicians should consider early empiric influenza antiviral treatment in HIV-infected patients presenting with suspected influenza [8]." Nevertheless, it is interesting that having severe impaired immune status, CD4+ count less than 200 cells/ $\mu$ l does not relate to poor clinical outcome or complication of swine flu infection [8]. Focusing on the immune response to the swine flu, according to a recent Thai report, it was found that "seroconversion occurred in approximately one third of the patients with swine flu [8]". It is also reported the observed pattern is not different between HIV-infected and HIV-uninfected cases [9]. Of interest, it seems that the clinical feature in HIV seropositive cases is not different from those with seronegativity. The proposal that HIV is an important risk for severe disease and fatality should be reappraised.

\section{Difficulty in Diagnosis and Treatment of Swine Flu in HIV Infected Cases}

It is no doubt that the HIV infection can be the serious underlying medical disorder in swine flu [10]. HIV is an important risk for having severe infection [10]. To diagnose the swine flu infection in patients with HIV infection, the standard diagnostic procedure, by molecular diagnosis, is needed [2]. Focusing on the imaging investigation, the pattern of pneumonia observed in case with underlying HIV infection is not different from that case without HIV infection [11]. Dosekun et al. Also raised an important note that the clinical feature of swine flu is a classical viral infection and it is the same as early HIV infection, hence, the early HIV infection might be misdiagnosed as swine flu in the period of swine flu outbreak [12]. Also, there are 
also several similar viral infections that might look like swine flu in HIV infected cases. Cunha et al. Noted that "during the influenza season, in adults hospitalized with HIV, the diagnostic possibilities should include influenza-like illnesses, e.g., human parainfluenza virus types 3 and 4, human metapneumovirus, and pertussis [13]."

As already noted, the impaired immune status does not contribute to severity of disease [8]. Nevertheless, López-Aldeguer et al. Found that "low CD4 lymphocytes correlated with longer hospitalization and bacterial infections [14]". López-Aldeguer et al. Also mentioned that "early oseltamivir treatment reduced severe symptoms [14]" Therefore, the earlier treatment is still warranted for any HIV infected patients $[7,8]$. Indeed, the early treatment should be given in any cases of swine flu regardless of HIV status [1,2]. Focusing on outcomes of oseltamivir treatment, according to a recent review, "most HIV-infected individuals recovered without major consequence [15]." However, Sheth et al. Noted that susceptibility to swine flu virus infection and severity of influenza illness did not increase in HIV-infected cases that had no advanced immunosuppression or comorbid conditions [16]. According to the observation by Ormsby et al., swine flu is usually more severe in HIV infected patients with late and advanced disease than those ones receiving standard antiretroviral therapy with good disease control [17]. Hence, the management of other comorbid conditions has to be included in the management plan of HIV infection with swine flu.

\section{Conclusion}

In clinical practice, swine flu can be seen in HIV infected cases with no doubt. There are some reported cases of HIV patients getting swine flu infection, which do not show a worse prognosis comparing to that of non-HIV patients. The author further suggested that not only suspected concurrent HIN infection in HIV infected patients should get early treatment but also awareness on misdiagnosis of influenza in HIV with other influenza like diseases is needed. Due to the impaired immunity, early diagnosis and prompt treatment for swine flu in HIV infected cases is required. As proposed by Ormsby et al. [17], standard antiretroviral therapy should be considered for all cases aiming at good outcome.

\section{References}

1. Wiwanitkit V. Public health management of swine flu. Respirology 2010;15(5):870. doi: 10.1111/j.1440-1843.2010.01783.x.

2. Wiwanitkit V. Swine flu: the present pandemic infectious disease. Kulak Burun Bogaz Ihtis Derg. 2009;19(2):57-61.

3. Rodríguez-Rieiro C, Carrasco-Garrido P, Hernández-Barrera V, López de Andrés A, Jimenez-Trujillo I, Gil de Miguel A, et al. Pandemic influenza hospitalization in Spain (2009): incidence, in-hospital mortality, comorbidities and costs. Hum Vaccin Immunother.2012;8(4):443-447. doi: 10.4161/hv.18911.

4. Del Rio C, Sierra-Madero J. Swine-origin influenza A (H1N1) and HIV.
The CDC offers guidance for HIV-infected patients potentially exposed to swine flu. J Watch AIDS Clin Care. 2009;21(6):51.

5. Enserink M. Swine flu outbreak.Worries about Africa as pandemic marches on. Science. 2009; 325(5941):662. doi: 10.1126/ science.325_662.

6. Koegelenberg CF, Irusen EM, Cooper R, Diacon AH, Taljaard JJ, Mowlana A, et al. High mortality from respiratory failure secondary to swineorigin influenza A (H1N1) in South Africa.QJM. 2010;103(5):319-25. doi: 10.1093/qjmed/hcq022.

7. Kulkarni R, Kinikar A, Valvi C. Clinical profile of H1N1 positive HIVinfected children. Indian Pediatr. 2011;48(2):131-2.

8. Peters PJ, Skarbinski J, Louie JK, Jain S, Roland M, Jani SG, et al. HIVinfected hospitalized patients with 2009 pandemic influenza A (pH1N1)-United States, spring and summer 2009. Clin Infect Dis. 2011;52 Suppl 1:S183-8. doi: 10.1093/cid/ciq036.

9. Garg S, Olsen SJ, Fernandez S, Muangchana C, Rungrojcharoenkit K, Prapasiri P, et al. Seroincidence of Influenza Among HIV-infected and HIV-uninfected Men During the 2009 H1N1 Influenza Pandemic, Bangkok, Thailand.Open Forum Infect Dis. 2014;1(3):ofu082. doi: 10.1093/ofid/ofu082.

10.LaRussa P. Pandemic novel 2009 H1N1 influenza: what have we learned? Semin Respir Crit Care Med. 2011;32(4):393-9. doi: 10.1055/s-0031-1283279.

11. Marchiori E, Zanetti G, Hochhegger B, Irion KL. High-resolution computed tomography findings in an HIV-positive patient with swineorigin influenza A (H1N1) virus-associated pneumonia. Br J Radiol. 2010;83(986):179. doi: 10.1259/bjr/93404758.

12. Dosekun O, Kober C, Richardson D, Parkhouse A, Fisher M. It's not all swine flu...are we missing opportunities to diagnose primary HIV infection in patients with flu symptoms? Int J STD AIDS. 2010;21(2):145-6. doi: 10.1258/ijsa.2009.009514.

13. Cunha BA, Syed U, Hage JE. Respiratory syncytial virus (RSV) community-acquired pneumonia (CAP) in a hospitalized adult with human immunodeficiency virus (HIV) mimicking influenza A and Pneumocystis (carinii) jiroveci pneumonia (PCP). Heart Lung. 2012;41(1):76-82. doi: 10.1016/j.hrtlng.2011.05.004.

14.López-Aldeguer J, Iribarren JA, Valencia E, Barquilla E, Knobel H, Santos J, et al. Outcomes in HIV-infected patients admitted due to pandemic influenza. Enferm Infecc Microbiol Clin. 2012;30(10):60812. doi: 10.1016/j.eimc.2012.02.007.

15. Cooper CL. Pandemic H1N12009 influenza and HIV: a review of natural history, management and vaccine immunogenicity.Curr Opin Infect Dis. 2012;25(1):26-35. doi: 10.1097/QC0.0b013e32834ef56c.

16. Sheth AN, Patel P, Peters PJ. Influenza and HIV: lessons from the 2009 H1N1 influenza pandemic.Curr HIV/AIDS Rep. 2011;8(3):181-91. doi: 10.1007/s11904-011-0086-4.

17.Ormsby CE, de la Rosa-Zamboni D, Vázquez-Pérez J, AblanedoTerrazas Y, Vega-Barrientos R, Gómez-Palacio M, et al. Severe 2009 pandemic influenza A (H1N1) infection and increased mortality in patients with late and advanced HIV disease.AIDS. 2011;25(4):435-9. doi: 10.1097/QAD.0b013e3283434844. 